\title{
Prioritising sites for pollinators in a fragmented coastal nectar habitat network in Western Europe
}

\author{
George B. Paterson • Gill Smart • Paul McKenzie $\mathbb{1} \cdot$ Sally Cook $\mathbb{C}$
}

Received: 27 April 2018/Accepted: 5 August 2019/Published online: 30 October 2019

(C) The Author(s) 2019

\begin{abstract}
Context Habitat loss and fragmentation contribute significantly to pollinator decline and biodiversity loss globally. Conserving high quality habitats whilst restoring and connecting remnant habitat is critical to halt such declines.

Objectives We quantified the connectivity of pollinator habitats for a generic focal species (GFS) which represented three groups of pollinators in an existing coastal nectar habitat network. Subsequently, in partnership with a conservation agency, we modelled an improved landscape that identified priority habitat patches to increase connectivity for pollinators.

Methods We selected 4260 pollinator habitats along an $80 \mathrm{~km}$ section of coastland in Scotland using Phase 1 habitat data. A GFS represented three vulnerable European pollinator groups while graph theory and spatial metrics were used to identify optimal sites that could enhance habitat connectivity.
\end{abstract}

Electronic supplementary material The online version of this article (https://doi.org/10.1007/s10980-019-00884-x) contains supplementary material, which is available to authorized users.

G. B. Paterson · P. McKenzie $(\bowtie) \cdot S$. Cook

School of Geography and Environmental Sciences, Ulster University, Coleraine BT52 1SA, Northern Ireland, UK

e-mail: sjp.mckenzie@ulster.ac.uk

G. Smart

Scottish Wildlife Trust, Unit 6 Kyle Business Park, Cunninghame Road, Irvine KA12 8JJ, UK
Results Higher dispersing species experienced greater habitat connectivity in the improved landscape and habitat availability increased substantially in response to small increases in habitat. The improved landscape revealed important habitat patches in the existing landscape that should be protected and developed.

Conclusions Our findings highlight that optimal landscapes can be designed through the integration of habitat data with spatial metrics for a GFS. By adopting this novel approach, conservation strategies can be targeted in an efficient manner to conserve atrisk species and their associated habitats. Integrating these design principles with policy and practice could enhance biodiversity across Europe.

Keywords GIS - Landscape planning · Potential connectivity $\cdot$ Habitat networks $\cdot$ Ecological networks $\cdot$ Pollination services

\section{Introduction}

Conserving biodiversity is essential for the sustainable functioning of ecosystems and the products and services they provide (Bennett et al. 2015). Water quality, food production, air quality, disease and pest control are some of the benefits resulting from a biodiverse landscape (MEA 2005; Wratten et al. 
2012). The role pollinators play in food production has received much attention over the past decade due to the rapid decline in honey bee (Smith et al. 2013; Bauer and Wing 2016) and wild bee (Cameron et al. 2011) populations. Potts et al. (2010) suggested that $75 \%$ of all human food crops are pollinated by insects, most of which are bees. It is therefore critical that factors affecting pollinator decline, such as habitat loss and fragmentation (Krauss et al. 2010; Haddad et al. 2015; Wray and Elle 2015), are a focus of conservation efforts.

The impact on pollinators of habitat fragmentation depends on landscape and population structure. Öckinger and Smith (2007) found that the abundance and richness of butterflies and bees in small seminatural field margins was reduced with increasing isolation from large semi-natural grassland habitat. Jauker et al. (2009) identified that the diversity of bee species was significantly reduced in agricultural landscapes when semi-natural grasslands were small or isolated. Other studies however suggest that isolation effects may be less pronounced provided the habitat in question is of high quality: research into the colonisation of restored heathland by butterflies concluded that although isolation from source populations did limit colonisation, habitat quality was of greater importance (WallisDeVries and Ens 2010). Such observations emphasise the importance of considering habitat quality measures, as well as target species' sensitivity to isolation during habitat restoration projects. It is also recognised that landscape level connectivity, as well as increasing the availability of quality habitat, is seen as an aid to species' adaptations and resilience to climate change (Heller and Zavaleta 2009).

Ecological modelling and geographic information systems

Geographic Information System (GIS) software and fragmentation analysis tools can be used to measure habitat health at various spatial scales and model modifications to the environment that can provide policy makers and conservationists with valuable tools to target resources. Habitat structural pattern indices can give rapid estimates of landscape connectivity but they lack the necessary information to provide reliable and consistent measures of actual species dispersal success (Calabrese and Fagan 2004). Species dispersal metrics can be determined on the ecology of focal species, such as the relationship between bee body length and dispersal distance (Heard et al. 2007; Sardiñas et al. 2016), or from direct measurements. Direct measurements provide the most accurate dispersal data, but are labour intensive and may only be suitable when a few habitat patches are of interest (Calabrese and Fagan 2004). One alternative to specific species data is to use a conceptual generic focal species (GFS) that can represent ecological characteristics of species or groups relevant to conservation efforts, and for which adequate speciesspecific data are unavailable (Watts et al. 2005). For instance, Watts et al. (2010) used two broad-leaved woodland GFS to evaluate the effects of fragmentation on 15 species with moderate or high sensitivity to fragmentation.

Functional connectivity considerations

In this study, graph theory is used as it lends itself particularly well to ecological applications involving landscape or habitat connectivity analysis (PascualHortal and Saura 2006; Decout et al. 2010). Most habitat fragmentation studies use a least-cost path (LCP) algorithm, rather than Euclidean measurements, for calculating the most efficient path for a species travelling between two habitat patches (Ayram et al. 2016). LCP typically involves the use of a raster map to represent a resistance matrix, with each cell given a value indicating the level of resistance the habitat imposes on the target species as it moves through the cell. However, the calculation of resistance values can be uncertain (Tewksbury et al. 2002; Aavik et al. 2014; Villemey et al. 2016). Furthermore, LCP is more suited to specific species rather than the GFS approach being adopted by the present study (Kupfer 2012).

\section{Project aims}

This study presents a novel method for assessing and improving pollinator range using a GFS approach. The work is in conjunction with Scotland's leading nature conservation charity, the Scottish Wildlife Trust (SWT), which supports a Nectar Network Partnership (NNP) aiming to connect and conserve habitats suitable for butterflies, moths and bees. 
The key aims of this study were: (1) to use GIS, GFS and spatial metrics based on graph theory to map key sites as part of a nectar network, (2) to aid the SWT's decision making process by highlighting areas within the landscape most suited as potential sites for connecting fragmented nectar habitats, (3) to highlight the most important existing habitat sites for conservation, and (4) to produce a reusable methodology for other, similar, UK or European landscapes.

\section{Methods}

Study area

The study area is composed of a zone stretching $5 \mathrm{~km}$ inland and covering $404 \mathrm{~km}^{2}$ between the coastal towns of Irvine and Girvan (Fig. 1). The Scottish Wildlife Trust (SWT) and Nectar Network chose this boundary because the dune and fixed dune coastal habitats have remnants of species-rich habitats and patches of pollinator diversity from which to provide further connections on both sand-based and non-sandbased land. Furthermore, by focussing on this small area, recommendations can be implemented more effectively as they do not exceed time and financial budgets of SWT.

Landcover datasets

The open source GIS software QGIS v. 2.18.0 was used to map spatial datasets and manipulate data. Some tasks were automated using a combination of QGIS workflow model and Python scripting interface (PyQGIS).

Phase 1 habitat spatial data in vector form for 2003-2006 were available for the study area. Phase 1 is a robust methodology developed by the Joint Nature Conservation Committee (JNCC) and is available across the United Kingdom for ten broad categories

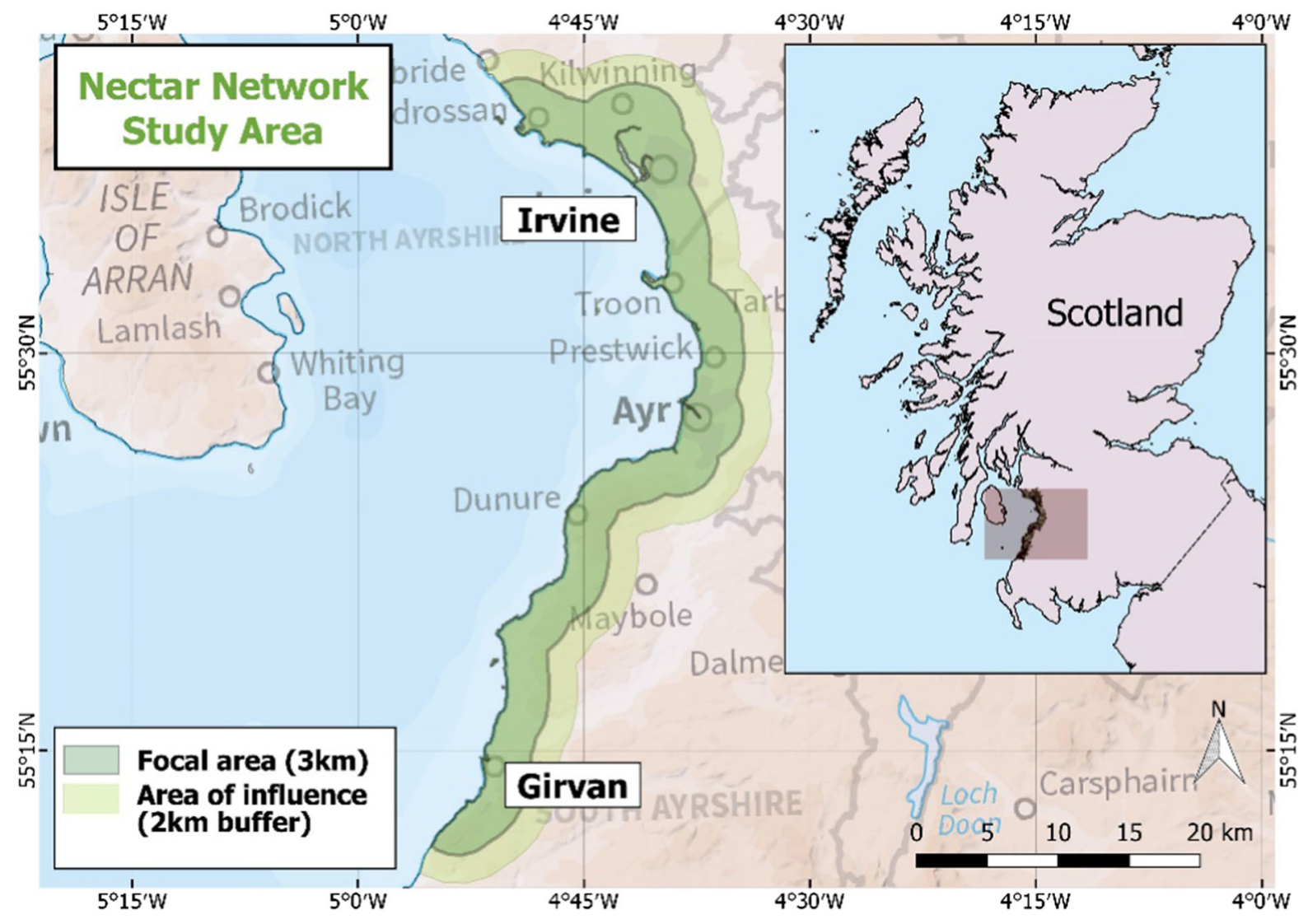

Fig. 1 Map showing area targeted for conservation efforts, and a $2 \mathrm{~km}$ zone of influence to ensure habitats that may contribute to nectar network connectivity outside of the focal area are considered 
(e.g. woodland and scrub) and 155 specific habitats (e.g. dense scrub). Phase 1 habitats are mapped and classified through well-established ground survey techniques (JNCC 2010) and provided a level of habitat identification accuracy greater than those derived from satellite imagery, and at a scale suitable for this target study area and species (Franklin et al. 2018). All Phase 1 habitats lying within or overlapping the study area were selected and Phase 1 codes of habitat that tend to support pollinators were identified using expert opinion from the SWT (Online Appendix Table 1), and a workflow set up in QGIS to select those habitats for analysis. A small percentage $(4 \%)$ of the landscape which related mainly to urban areas was not included in the Phase 1 data.

While the UK National Biodiversity Network database recorded 316 Lepidoptera species and 22 Apidae species in the study area from 2009 to 2018 (NBN Atlas 2019), pollinator species presence data were not used in this study to identify habitat types suitable for the three groups of pollinators since this may have excluded suitable habitat where species survey data was lacking. Furthermore, there is evidence of strong correlations between habitat type and suitability for species (Bunce et al. 2013). Many of the nectar habitat types selected (Online Appendix Table 1), such as raised and blanket bog, dune grassland and dune heath and unimproved calcareous grassland, are EU Habitats Directive Annex I priority habitats, therefore their protection is important at a European level.

A useful indicator of habitat quality can be established if it lies within or partly within a designated or proposed Wildlife Site. Such sites are often maintained through sensitive habitat management practices (Selman 2009), and must reach a certain quality standard before being designated, for example Sites of Special Scientific Interest (Spash and Simpson 1992) and subsequently managed for biodiversity (Hodgson et al. 2010). Vector dataset layers for proposed and designated Wildlife Sites for the study area were acquired directly from the SWT and were used in combination with habitat area to indicate quality.

\section{Target species}

This study used a GFS to represent three species groups, namely butterfly, moths and bees. The approach was adapted from the neighbouring Glasgow and Clyde Valley (GCV) and Falkirk Integrated Habitat Network projects (Moseley et al. 2008; Smith et al. 2008). Both projects used a resistance matrix to predict the effective distance between habitat patches based on their GFS traits. An edge-to-edge Euclidean metric, shown by Lander et al. (2013) to effectively represent pollinator movements, was deemed appropriate for this study as the study area is mainly agricultural and boundaries between pollinator and non-pollinator patches have a low contrast and are more permeable (Ewers and Didham 2007). To represent their grassland GFS, the GCV study used nine butterfly species of conservation concern, also present in this study's landscape, with a mean dispersal of $500 \mathrm{~m}$ and maximum dispersal of $2 \mathrm{~km}$ while the Falkirk study chose $500 \mathrm{~m}, 1 \mathrm{~km}$ and $2 \mathrm{~km}$. Lower distance thresholds are used in this study to account for the Euclidean versus resistance matrix methodology and the moderate negative effect intensive agriculture has on species mobility. For micro and macro-moth species Fuentes-Montemayor et al. (2011) recommended a maximum distance between habitats of $250 \mathrm{~m}$ while Merckx et al. (2012) also used a $250 \mathrm{~m}$ threshold for micro-moth species, but $800 \mathrm{~m}$ for macro moth species. Due to a lack of consistent data on bee dispersal, the present study used foraging ranges to estimate the distance thresholds suited to the bees group. More reliable data appear to exist on foraging ranges, and it is known that access to high quality foraging habitat is very important for bee population health (Carvell et al. 2011; Warzecha et al. 2016). One study recorded a mean foraging distance of $250 \mathrm{~m}$ for the smallest UK solitary bee species (Nowakowski and Pywell 2016), whilst an earlier study found foraging distances for four bumble bee species ranging from 450 to $758 \mathrm{~m}$ (Knight et al. 2005). For this study, three thresholds of $250 \mathrm{~m}$, $500 \mathrm{~m}$ and $1 \mathrm{~km}$ were used to represent mean (lowest) through to maximum dispersal or foraging range, adequately covering a range of pollinator species within the three target groups of butterflies, moths and bees.

Evaluating habitat availability and patch importance

The Conefor 2.6 plugin for QGIS was used to produce connectivity calculations relating to the edge to edge 


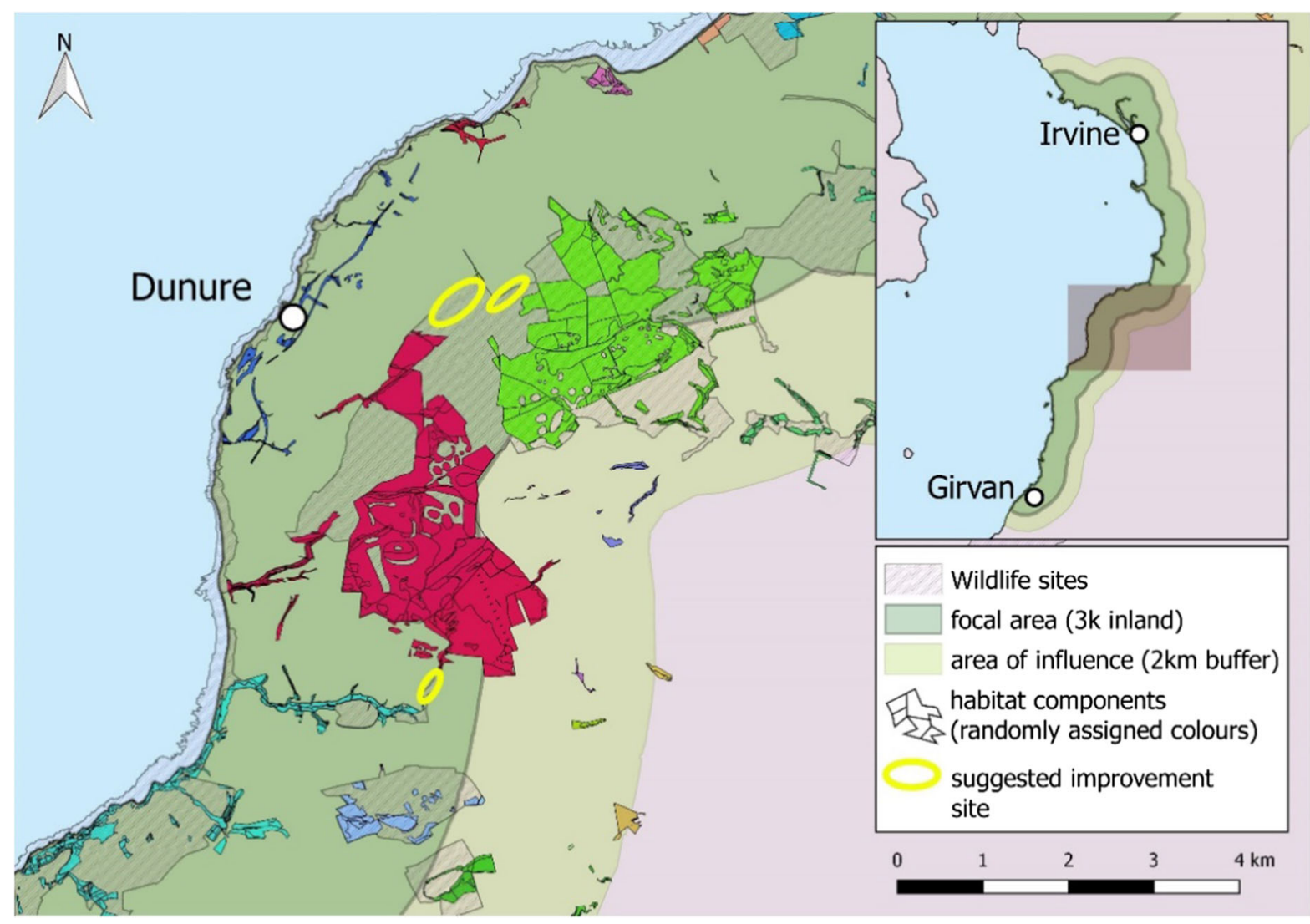

Fig. 2 Example of a group of suggested sites for stepping-stone habitats between unconnected components for a $250 \mathrm{~m}$ dispersal threshold. Components shown in randomly selected colours

distance in metres between every pair of habitat patches, and the quality measure of every habitat patch, given by:

quality $_{p}=$ area $_{p}+$ area $_{w}$

where area $_{p}$ is the habitat area in $\mathrm{m}^{2}$, and area $_{w}$ is the area within patch $p$ occupied by proposed or designated Wildlife Sites. Where Wildlife Sites intersect a pollinator habitat, the area of intersection is added to the quality measure to ensure their positive impact is included in the connectivity analysis.

For each of the three distance thresholds, two landscape-level metrics were chosen to quantify connectivity: (1) Integral Index of Connectivity (IIC) and (2) Number of Components (NC). IIC represents overall habitat availability (reachability) and is a measure of the amount of habitat available to an organism within a network of patches based on habitat area (or some other quality attribute), and their interand intra-patch connections given some dispersal- related property. Habitat patches are represented as nodes while dispersal-related distances determine the existence or absence of a link between each pair of habitat patches. IIC increases from 0 to 1 as connectivity increases with a value of 1 representing maximum connectivity in a landscape. IIC is given by:

$I I C=\frac{\sum_{i=1}^{n} \sum_{j=1}^{n} \frac{a_{i} \cdot a_{j}}{1+n l_{i j}}}{A_{L}^{2}}$

where $\mathrm{n}$ is the total number of nodes, $a_{i}$ and $a_{j}$ are the areas (or some other quality measure) of patches $i$ and $j, n l_{i j}$ is the number of links in the shortest path (topological distance) between patches $i$ and $j$, and $A_{L}$ is the total landscape area, consisting of both habitat and non-habitat areas (Pascual-Hortal and Saura 2006). Studies have found that the IIC is an effective binary index for optimising landscape connectivity in conservation planning (Pascual-Hortal and Saura 2006; Saura and Pascual-Hortal 2007). In agreement 
(a)

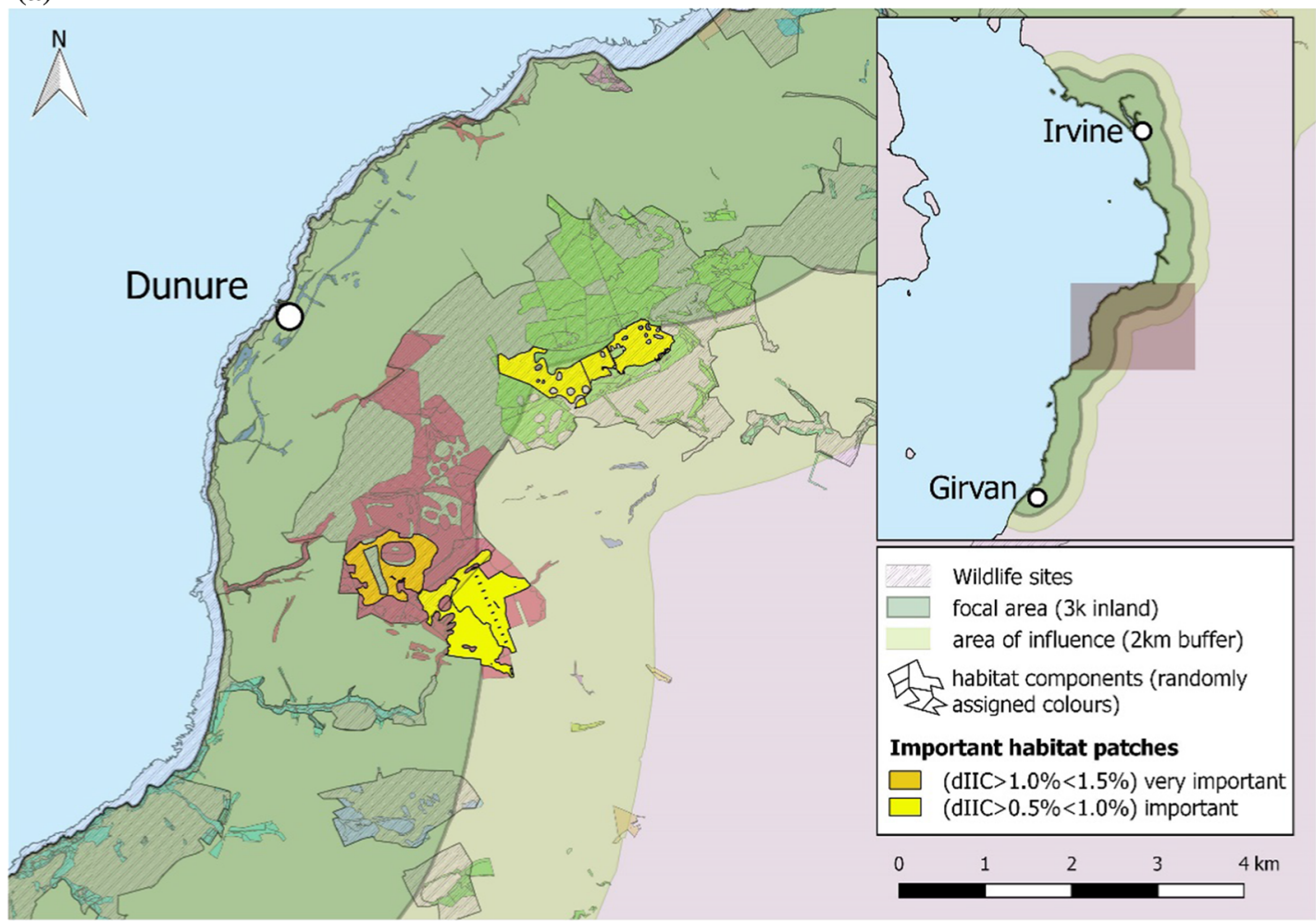

(b)

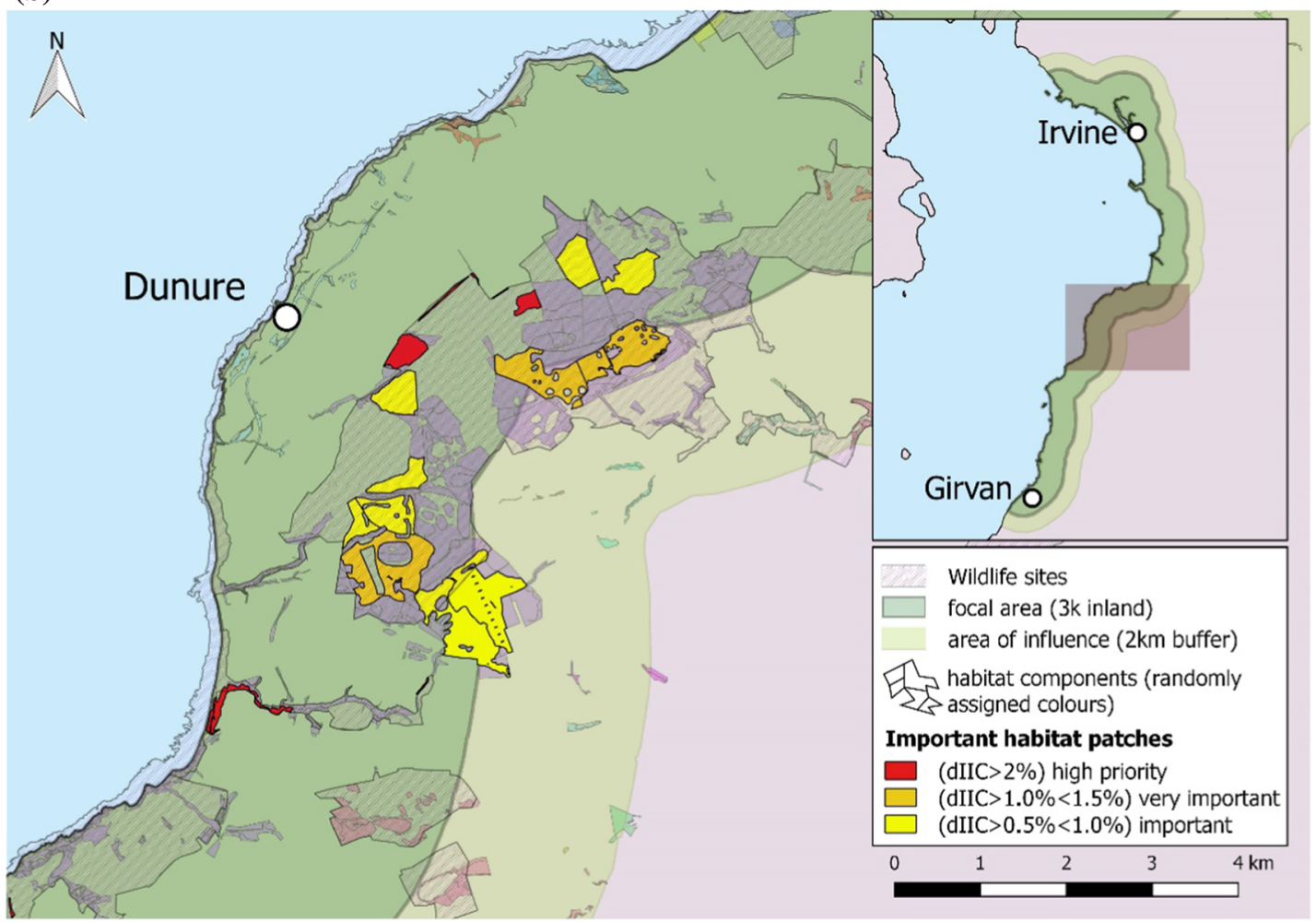


4Fig. 3 Example portion of the Irvine to Girvan landscape showing detail of components and important habitats at a $250 \mathrm{~m}$ threshold before and after the introduction of three proposed stepping stone habitats: a existing landscape and $\mathbf{b}$ improved landscape

with Fourie et al. (2015), we believe this metric balances data requirements with detail of results, and can cope computationally with large numbers of nodes (patches), whilst still being flexible enough to deal with additional information. Euclidean measurements were used to represent the shortest path between patches (Watts et al. 2010).

A component is a collection of habitat patches for which a path exists between every two habitat patches based on some distance-related threshold. NC represents the number of such components within the landscape. NC decreases as connectivity improves with a value of 1 representing paths between every pair of habitat patches in the landscape.

The dIIC patch metric was also calculated to quantify the percentage change in the overall IIC metric should a patch (node) be removed from the landscape, given by:

dIIC $(\%)=100 \cdot \frac{I I C-I I C_{\text {remove }}}{I I C}$ where IIC is the overall landscape IIC and $I I C_{\text {remove }}$ is the IIC value following the patches removal. The higher the $d$ IIC value, the greater the patch's contribution to overall connectivity (habitat availability). The $d$ IIC values help to prioritise the most important patches for conservation.

Mapping the existing network

For each distance threshold, the patch component number and $d$ IIC value were joined with the habitats layer in QGIS. Individual components and the most important habitat patches (highest $d$ IIC values) were highlighted in separate layers for each of the distance thresholds. Appropriate GIS rule-based illustration styles were applied to the most important habitat patches in the landscape ( $d$ IIC $>0.5 \%<1 \%$; $d$ IIC $\geq 1 \%<1.5 \% ; d \mathrm{IIC} \geq 1.5 \%<2 \% ; d \mathrm{IIC} \geq 2$ ).

Improving the habitat network

Once the habitat layer had patch metrics, the extent of each network could be deduced via the component layer for each distance threshold. Based on each component's size, location, number of high value patches (high $d \mathrm{IIC}$ ) and proximity to other
Table 1 Land use within study area

\begin{tabular}{lll}
\hline Study area landscape type (Phase 1) & Area $\left(\mathrm{km}^{2}\right)$ & Area coverage $(\%)$ \\
\hline Farmland & 218 & 54.0 \\
Nectar habitat & 121 & 30.0 \\
Non-pollinator woodland/forest habitat & 24 & 6.0 \\
Built area & 20 & 5.0 \\
Amenity grassland & 14 & 3.5 \\
Other & 6 & 1.5 \\
\hline
\end{tabular}

Table 2 Overall IIC and NC for three dispersal/foraging thresholds before and after proposed connectivity improvements

\begin{tabular}{lllllll}
\hline Dispersal/foraging threshold $(\mathrm{m})$ & \multicolumn{6}{l}{ Measure of connectivity } \\
\cline { 2 - 7 } & IIC (before) & IIC (after) & IIC change (\%) & NC (before) & NC (after) & NC change (\%) \\
\hline 250 & 0.0029069 & 0.0033506 & +15 & 157 & 147 & -6 \\
500 & 0.0047237 & 0.0053328 & +13 & 41 & 31 & -24 \\
1000 & 0.0067475 & - & - & 3 & - & - \\
\hline
\end{tabular}

Percentage increase in IIC and decrease in NC are relative to the original overall indices. Connectivity improvements were not modelled at the $1000 \mathrm{~m}$ threshold due to the original landscape NC index at this threshold indicating almost full habitat connectivity 
(a)

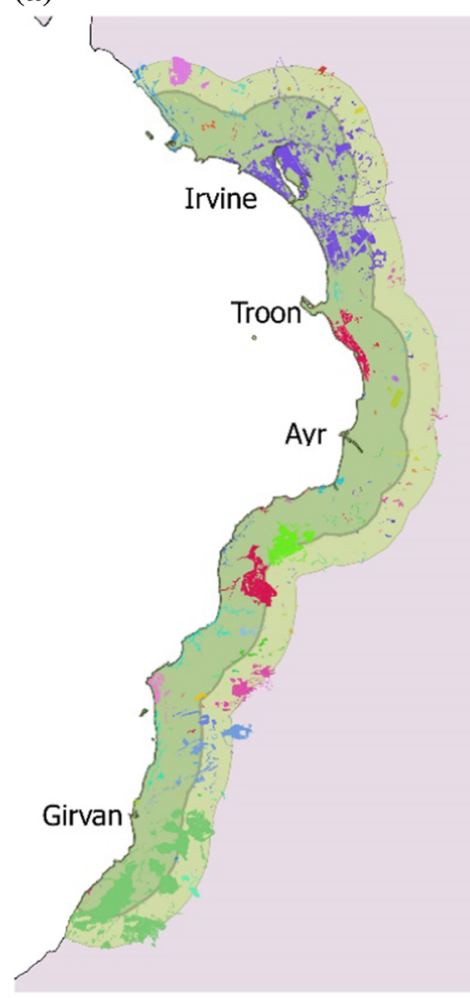

(d)

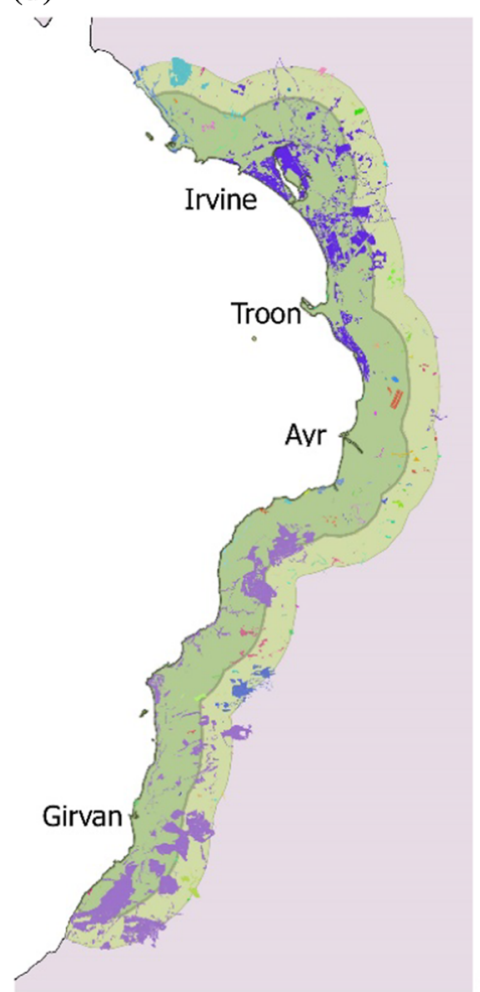

(b)

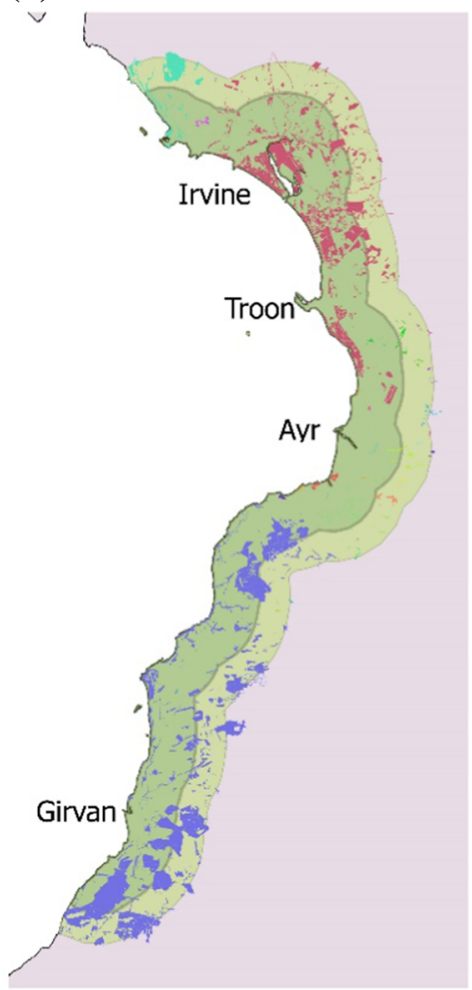

(c)

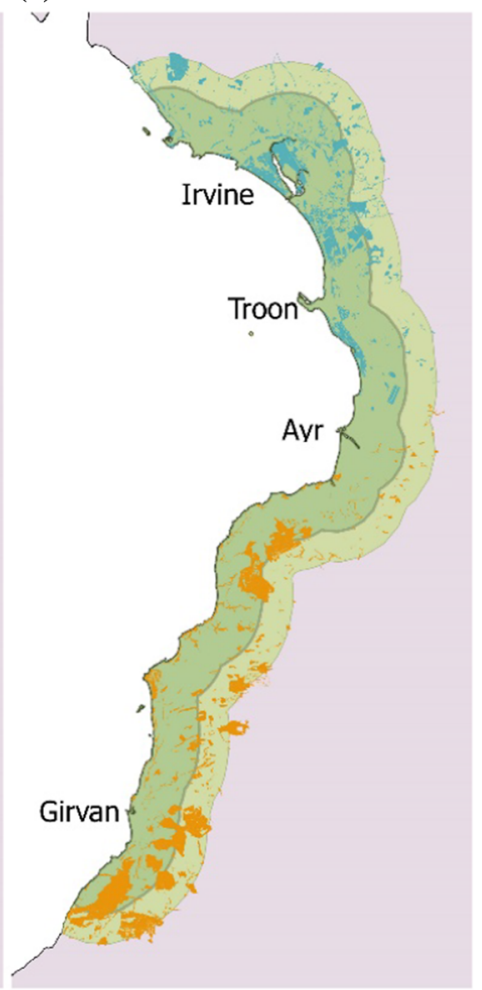

(e)

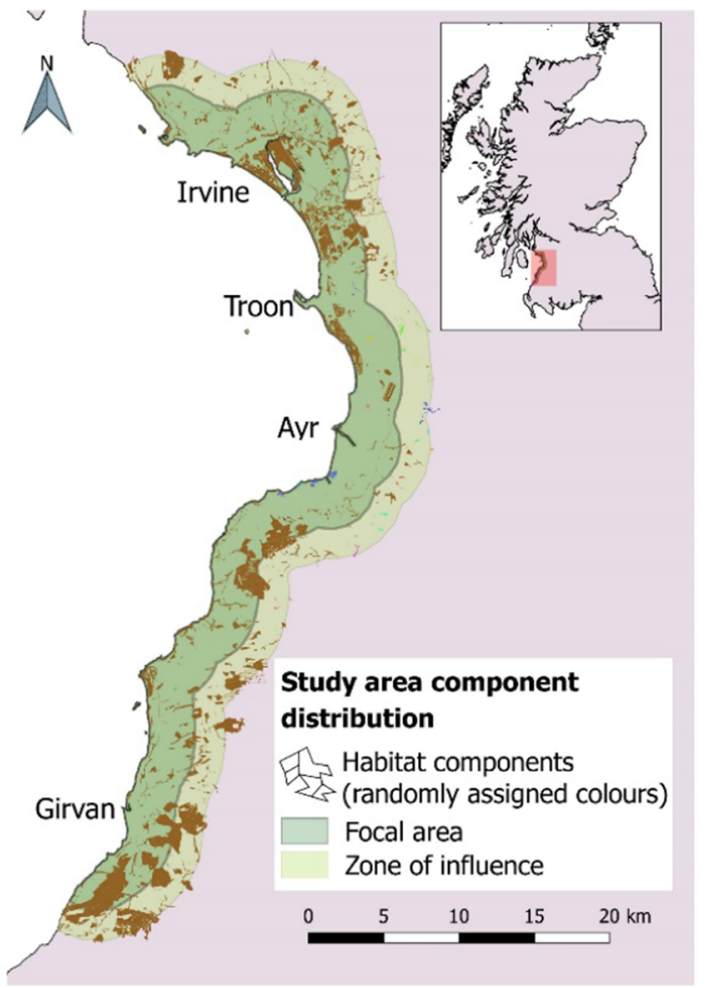


4Fig. 4 Location of habitat components based on three distance thresholds in the existing Irvine to Girvan landscape: a $250 \mathrm{~m}$, b $500 \mathrm{~m}$ and c $1000 \mathrm{~m}$. Simulation of component structure after addition of proposed habitats at d $250 \mathrm{~m}$ and e $500 \mathrm{~m}$ thresholds. Simulated improvements were not applied to the model at $1000 \mathrm{~m}$ threshold. Similar colours indicate interconnected habitat patches (components)

components, suitable sites were chosen for proposed new habitat patches to connect components (Figs. 2, 3a).

Potential connecting sites at the $250 \mathrm{~m}$ threshold were manually added to the selected habitats layer and the same process was repeated for the $500 \mathrm{~m}$ threshold. However, this process was not repeated at $1000 \mathrm{~m}$ since there were only three components and the positions of the connections made at $500 \mathrm{~m}$ would have completely connected the $1000 \mathrm{~m}$ network. The entire process of evaluating habitat availability and patch importance, followed by mapping in QGIS, was repeated for the improved landscape at the $250 \mathrm{~m}$ and $500 \mathrm{~m}$ thresholds, thus producing layers displaying components and important patches (dIIC) at these thresholds as well as the corresponding overall IIC and NC metrics (Fig. 3b).

\section{Results}

The existing habitat network is highly fragmented and heavily dominated by farmland (Table 1).

\section{Existing landscape}

The overall IIC values for all three distance thresholds are close to zero, indicating high fragmentation. IIC rose by $62 \%$ between the 250 and $500 \mathrm{~m}$ thresholds, and $43 \%$ between 500 and $1000 \mathrm{~m}$ (Table 2). The results show that pollinators with greater foraging or dispersal ability have access to a greater amount of habitat (higher IIC) than those that are more limited. $\mathrm{NC}$ decreased noticeably between 250 and $500 \mathrm{~m}$ (74\%), and between 500 and $1000 \mathrm{~m}(93 \%)$ (Table 2; Fig. $4 \mathrm{a}-\mathrm{c}$ ). As connectivity increases, NC decreases due to fewer isolated groups of connected habitat patches. At $1000 \mathrm{~m}$ only three habitat components were unconnected to the north, south and east of Ayr (Table 2; Fig. 4c).
Relatively few important habitat patches $(d \mathrm{IIC}>$ $0.5 \%$ ) were identified at all threshold levels. At the $250 \mathrm{~m}$ threshold, only 81 patches had a $d \mathrm{IIC}>0.5 \%$. Of these, only 15 were classed as high priority ( $d$ IIC value $>2 \%$ ) with the highest individual value equal to $8 \%$. The majority of the most important patches are located to the south of Girvan. A smaller number of important patches can be found near Irvine and also south of Troon and east of Dunure (Fig. 5a). At the $500 \mathrm{~m}$ threshold, 83 patches had a $d \mathrm{IIC}>0.5 \%$, but there were fewer patches (11) than at $250 \mathrm{~m}$ that were high priority $(d \mathrm{IIC}>2 \%)$. The highest $d$ IIC for a patch at $500 \mathrm{~m}$ was $11 \%$. There was a greater spread of important patches across the landscape at $500 \mathrm{~m}$ and $1000 \mathrm{~m}$ thresholds compared to $250 \mathrm{~m}$, but the majority were clustered around the towns of Irvine and Girvan for all thresholds (Fig. 5a-c). Many of the important patches were partially, or entirely, within designated or proposed Wildlife Sites.

\section{Improved landscape}

The improved landscape modelled the effects of the addition of strategically placed patches in the existing landscape with the aim of increasing overall habitat availability (IIC). Compared to the existing landscape results, IIC rose by $15 \%$ at the $250 \mathrm{~m}$ threshold with the addition of 11 habitat patches, representing $0.063 \%$ of the total existing pollinator habitat area. At $500 \mathrm{~m}$, the IIC increased by $13 \%$ with the addition of 14 new patches, representing $0.185 \%$ of the total existing pollinator habitat area (Table 2). Both scenarios indicate large gains in habitat availability relative to very modest habitat improvements. The mean patch size and quality measure of the additional habitats were significantly lower than the overall habitat mean at both $250 \mathrm{~m}$ and $500 \mathrm{~m}$ thresholds (Table 3). Greatest gains appear to be at the $250 \mathrm{~m}$ threshold with a marginally greater IIC increase than at $500 \mathrm{~m}$ (Table 2) and for approximately one-third the amount of additional habitat $(0.063 \%$ extra compared to $0.185 \%$ ).

The proposed new patches led to improved connectivity at both $250 \mathrm{~m}$ and $500 \mathrm{~m}$ thresholds, with 117 important patches $(d \mathrm{IIC}>0.5 \%)$ at $250 \mathrm{~m}$ and 100 important patches at $500 \mathrm{~m}$ (Fig. 5). The increases could be attributed to the positive effect of the placement of the additional habitats on habitat availability. This was also reflected in a noticeable 
(a)

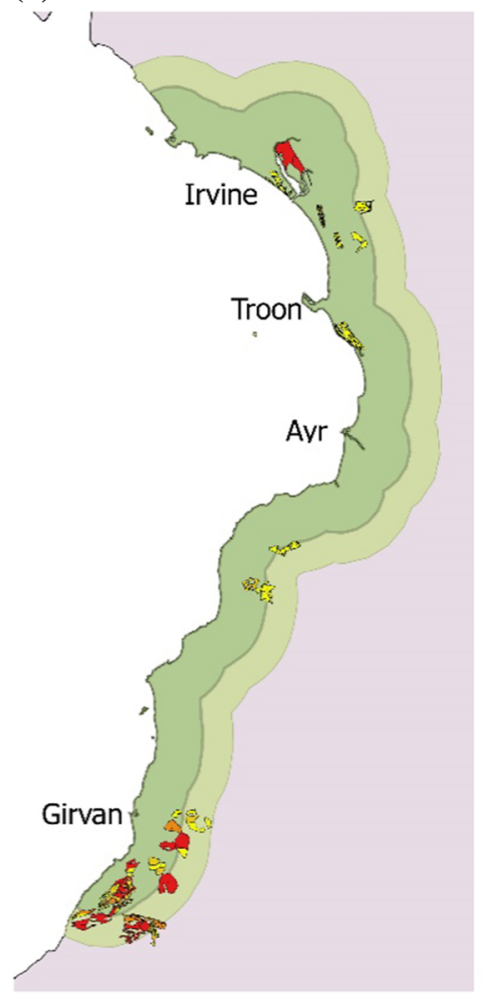

(d)

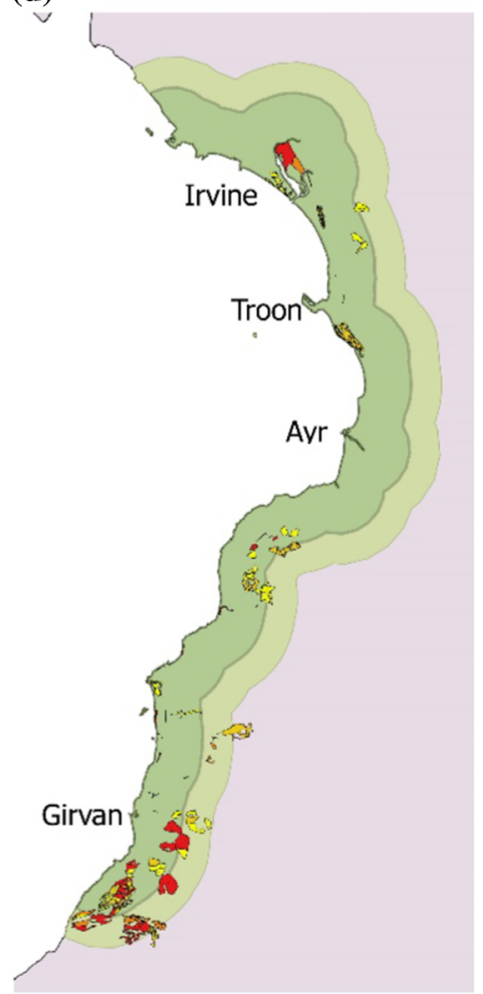

(b)

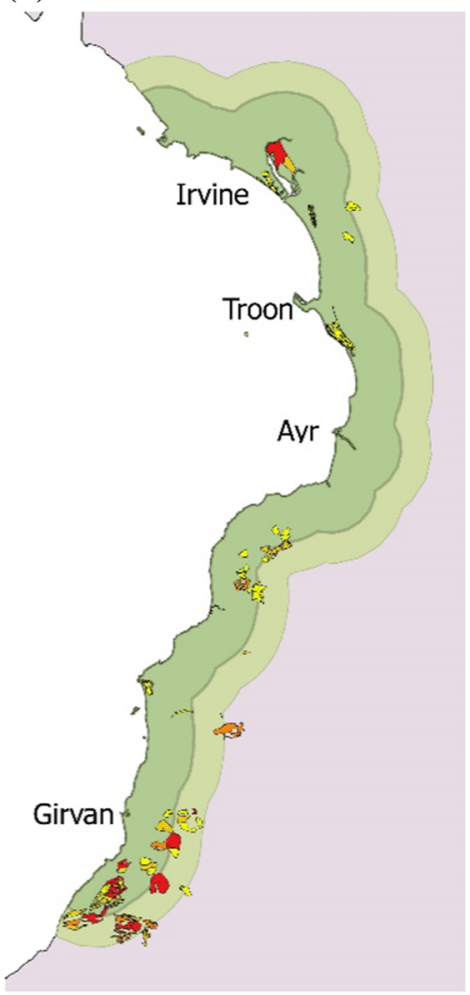

(c)

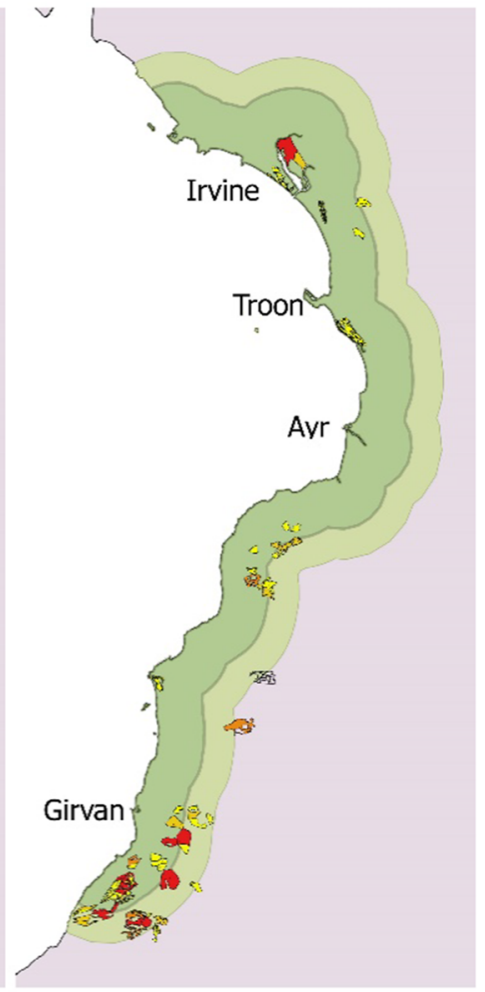

(e)

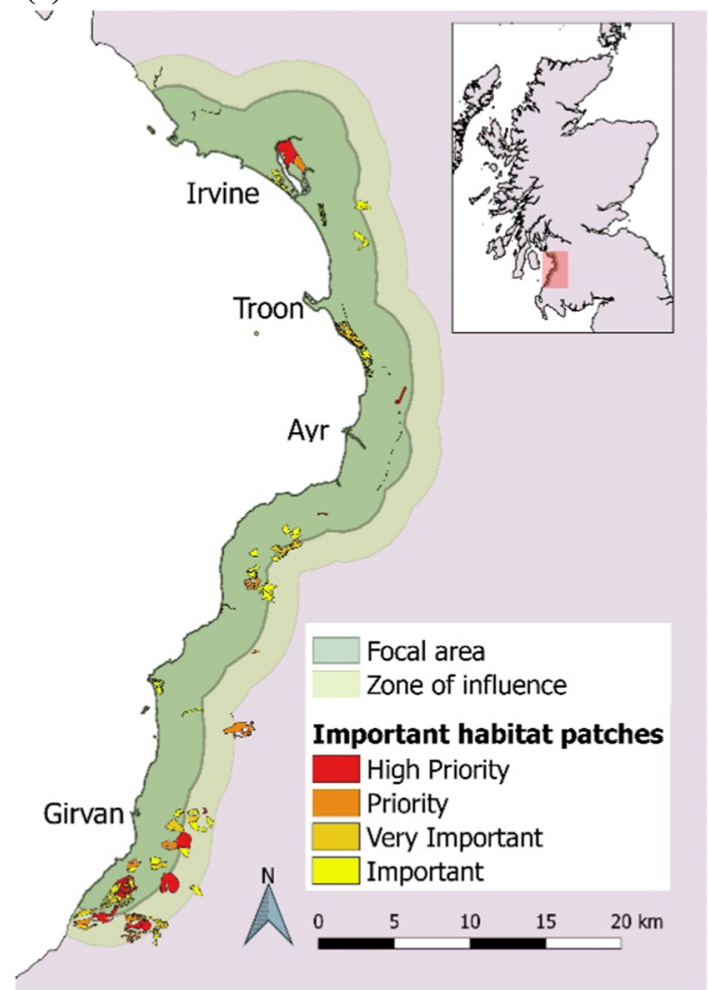


4 Fig. 5 Location of the most important habitat patches according to the $d \mathrm{IIC}$ metric before and after the simulated addition of connecting habitats. Existing landscape results for three distance thresholds: a $250 \mathrm{~m}, \mathbf{b} 500 \mathrm{~m}$ and c $1000 \mathrm{~m}$. Simulated results at d $250 \mathrm{~m}$ and e $500 \mathrm{~m}$. Importance levels in descending order of importance: high priority ( $d \mathrm{IIC} \geq 2 \%$ ), priority $(d \mathrm{IIC} \geq 1.5 \%$ $<2 \%)$, very important $(\mathrm{dIIC} \geq 1 \%<1.5 \%)$ and important $(d \mathrm{IIC}>0.5 \%<1 \%)$. Simulated improvements were not applied to the model at the $1000 \mathrm{~m}$ threshold

increase in the number of habitat patches with $d \mathrm{IIC}>2 \%$, increases of 19 and 13 at $250 \mathrm{~m}$ and $500 \mathrm{~m}$ thresholds respectively. Most of the added patches produced $d$ IIC values in the high priority bracket $(>2 \%)$, as shown by their high mean $d \mathrm{IIC}$ values (Table 3). NC decreased to $147(-6 \%)$ at $250 \mathrm{~m}$, and to $31(-24 \%)$ at $500 \mathrm{~m}$ (Table 2). The largest component at the $250 \mathrm{~m}$ threshold covered $53 \%$ of habitat, increasing from $25 \%$ before improvement (Fig. 4a, d). There was also a large increase from 60 to $98 \%$ at $500 \mathrm{~m}$ (Fig. $4 \mathrm{~b}, \mathrm{e}$ ). There was a trend towards an increase in component size as $\mathrm{NC}$ decreased. After improvement at the $500 \mathrm{~m}$ threshold the landscape was almost completely connected, with only $2 \%$ of habitat isolated from the main component (Fig. 4e).

\section{Discussion}

This study used landscape metrics and GIS to quantify the spatial configuration of pollinator habitats in a coastal landscape, not only to describe the current habitat but also to design an improved landscape with increased connectivity for pollinators. Analysis found that significant gains for pollinators could be made in highly-fragmented landscapes by making small, targeted conservation actions and revealed high priority habitat patches in the existing landscape matrix which may not have been evident from landscape habitat availability calculations prior to improvement.

Improving habitat availability

In this highly fragmented landscape the majority of the patches $(n=4260)$ are relatively small, with $55 \%$ of habitat patches less than $5000 \mathrm{~m}^{2}$. This could have detrimental consequences for species richness, abundance and viability, for example for specialised butterfly species in small isolated patches. Brückmann et al. (2010) found the proportion of specialised butterfly species was significantly higher in larger habitat patches $\left(24,000 \pm 2000 \mathrm{~m}^{2}\right)$, while Watts et al. (2010) found smaller habitat patches $\left(1200 \pm 200 \mathrm{~m}^{2}\right)$ can reduce richness, but this may be significantly improved through habitat patch connectivity. Similarly, with increasing foraging habitat size wild bee species richness (Steffan-Dewenter 2003; Bommarco et al. 2010; Hopfenmüller et al. 2014) as well as density (Blaauw and Isaacs 2014) tend to increase. In this study, we identified several large habitats $\left(>25,000 \mathrm{~m}^{2}\right)$ of high importance and quality in the existing landscape, as shown by high $d$ IIC values (Fig. 5a-c). The high importance of these existing patches confirms previous research that habitat quality should be given the same attention as connectivity in conservation planning (Hodgson et al. 2009, 2011; WallisDeVries and Ens 2010; Watts et al. 2010). Important habitats could act as source populations for more vulnerable satellite populations (Hanski and Ovaskainen 2003) and protecting these habitats should be a priority for local policy makers and conservation agencies. It is proposed that pressure on potential source habitats should be reduced by increasing connectivity between components. The improvements achieve this by reducing the number of components at both the $250 \mathrm{~m}$ and $500 \mathrm{~m}$ thresholds. Additionally, the largest component increased in

Table 3 Comparison between patch metric mean values for habitat added to the landscape and overall habitat in the improved landscape simulation

\begin{tabular}{|c|c|c|c|c|c|c|}
\hline \multirow[t]{2}{*}{ Habitat coverage } & \multicolumn{2}{|c|}{ Area mean $\left(\mathrm{m}^{2}\right)$} & \multicolumn{2}{|c|}{ Quality mean } & \multicolumn{2}{|c|}{$d \mathrm{IIC}$ mean $(\%)$} \\
\hline & $250 \mathrm{~m}$ & $500 \mathrm{~m}$ & $250 \mathrm{~m}$ & $500 \mathrm{~m}$ & $250 \mathrm{~m}$ & $500 \mathrm{~m}$ \\
\hline All & 17,036 & 17,045 & 25,260 & 25,256 & 0.08 & 0.08 \\
\hline Added only & 4142 & 9642 & 7044 & 9642 & 3.91 & 5.69 \\
\hline
\end{tabular}


habitat area coverage by $28 \%$ at $250 \mathrm{~m}$, and by $38 \%$ at $500 \mathrm{~m}$. Metapopulation theory proposes that by increasing the metapopulation in this way, the probability of pollinator immigration into satellite habitats is increased, therefore reducing the likelihood of local extinctions (Hanski and Ovaskainen 2003; Eriksson et al. 2014).

The overall habitat availability (IIC) increases were substantial in relation to the amount of new habitat added; analysis showed a $15 \%$ gain in IIC for an additional $0.063 \%$ of habitat at $250 \mathrm{~m}$, and $13 \%$ gain in IIC for an additional $0.185 \%$ at $500 \mathrm{~m}$. Those increases can largely be attributed to the connections made between many of the largest components, potentially supporting more robust metapopulations (Crooks and Sanjayan 2006). Such large gains identified using graph theory and habitat availability metrics do not appear to be uncommon. Fourie et al. (2015) reported a 33\% increase in IIC for an $11 \%$ increase in habitat through the inclusion of abandoned croplands in a grassland biome in South Africa. While these croplands were an existing feature in the landscape, we propose that new habitat be created within the landscape. The potential benefits of which have been demonstrated by a forest restoration project that showed an increase in habitat availability of $5518 \%$ for an additional $10.5 \%$ of habitat created (Crouzeilles et al. 2015).

\section{Addition of individual patches}

The study area was dominated by farmland which limited the opportunities for the addition of sizeable connecting habitat patches able to sustain viable pollinator populations. Hence, the patches added tended to be small, linear habitats along agricultural field margins, which can be less suited to butterfly reproduction due to greater exposure to edge effects (Brown and Crone 2016). The additional patches are, therefore, more likely to operate as sink habitats, but can still play an important role in offering alternative foraging and nesting habitat for bee species (Heard et al. 2007), as well as a gene dispersal mechanism between connected habitats (Krewenka et al. 2011). This is reflected in the very high mean $d \mathrm{IIC}$ values for the added patches at the $250 \mathrm{~m}(3.91 \%)$ and $500 \mathrm{~m}$ (5.69\%) thresholds, well above the $2 \%$ minimum for high priority patches (Table 3 ). The importance of these patches is likely a function of their stepping- stone role which can be a valuable contributor to species persistence and long-distance dispersal (Saura et al. 2014) as well as promoting pollinator diversity (Menz et al. 2011). Furthermore, nectar strips can benefit farmers through ecosystem services such as pest control and crop pollination (Vialatte et al. 2017).

\section{Habitat connectivity modelling}

The most important habitat patch in the existing landscape at $500 \mathrm{~m}(\mathrm{dIIC} 11 \%)$ was unimportant at the $250 \mathrm{~m}$ threshold. On closer inspection, it connected two large components at the $500 \mathrm{~m}$ threshold, but not at $250 \mathrm{~m}$. Consequently, the area surrounding the patch will likely show an opportunity to join unconnected components at the $250 \mathrm{~m}$ threshold, something which may otherwise have been overlooked without the $500 \mathrm{~m}$ modelling. This suggests that examining results from one distance threshold may reveal information relevant to conservation planning at other thresholds.

\section{Benefits of improved landscape modelling}

One of the goals of conservation planning is anticipating the consequences of future anthropogenic activity or inactivity and putting in place pre-emptive measures should those actions have negative effects on the landscape. Our analysis identified specific habitat patches that appeared to have low importance in the existing landscape, yet form a critical function for pollinators in the improved landscape. For example, two patches in the existing landscape (Fig. 3a) are of low importance ( $d \mathrm{IIC}<0.5 \%)$ yet these two patches have high importance $(d \mathrm{IIC}>2 \%)$ in the improved landscape (Fig. 3b). This suggests that the model can help to "future proof" a habitat network by giving advanced warning of important sites for connectivity before any potentially damaging changes take place. Vos et al. (2008) identified connectivity as a means of tackling climate change effects on vulnerable species by increasing dispersal potential in response to changes in the suitability of existing habitat. Budgets often constrain the number of sites that can be managed and protected by conservation bodies. However, Alagador et al. (2014) proposed a framework to schedule the release of conservation areas when climate change forces species away from those areas, allowing the conservation body to 
prioritise new sites which would then, based on the frameworks prediction model, have suitable habitat available at that point in time.

\section{Recommendations and conclusions}

In the context of the present study, we recommend that pre-improvement patches with $d \mathrm{IIC}>2 \%$ are prioritised for protection, and suggest that patches with $d$ IIC $>1 \%$ are also considered where most appropriate. The mean quality measure of the highest priority patches is 40 times that of the mean habitat patch so their protection seems to be in line with other studies which claim that habitat size and quality are as important as connectivity for maintaining viable species populations (Forup et al. 2008; WallisDeVries and Ens 2010; Hodgson et al. 2009, 2011). In the improved landscape, however, the additional habitats possess mean quality measures which are small in comparison to the mean quality measure of all habitats at both the $250 \mathrm{~m}$ and $500 \mathrm{~m}$ thresholds (Table 3). This is mainly due to their stepping-stone role, but despite this, their mean $d$ IICs are in the high priority bracket $(>2 \%)$ (Table 3$)$. Their high values are reflected in the substantial increases in overall habitat availability. This is in line with Doerr et al. (2011) who believe that features facilitating dispersal in nonbreeding habitat are at least of equal importance as those focusing on habitat area and quality alone. While further research is required, we recommend that local policy makers and conservation agencies give consideration to such methodologies in order to maximise network connectivity.

The methodology used in this study is suitable for use in other landscapes where GFS are used and the coverage of significant barriers to dispersal is low. However, it is not recommended for individual species studies or for landscapes where the coverage of significant barriers to dispersal is high. In those situations, resistance matrixes are more appropriate, yet they add additional cost in terms of time, resources and money. The IIC and $d$ IIC measures in this study did not take into consideration habitat shape or edge effects as the GFS approach would have complicated the prediction of edge effects. However, future studies using a resistance matrix, and focusing on an individual species where edge effects have an influence on population abundance for example, may consider the quality attribute of a patch as a function of its area relative to its perimeter. This would help to account for the differences in edge effects between patches of varying size and shape.

The UK Phase 1 habitat survey data used in this study is readily transferable to the European Nature Information System (EUNIS) habitat classification system. EUNIS classifications are used across Europe, and member states are required by the INSPIRE Directive to use EUNIS codes to ensure habitat data compatibility throughout the EU (Strachan 2017).

In conclusion, habitat availability indices based on graph theory can be used in conservation planning at the landscape level to identify important habitat patches for conservation and connectivity at various dispersal thresholds to account for different species groups. Comparing results between an existing landscape and an improved landscape is an effective way to reveal important conservation opportunities which may be overlooked by analysis of existing landscape structure and function alone.

Acknowledgements Special thanks to the Scottish Wildlife Trust for provision of valuable datasets and guidance.

Open Access This article is distributed under the terms of the Creative Commons Attribution 4.0 International License (http:// creativecommons.org/licenses/by/4.0/), which permits unrestricted use, distribution, and reproduction in any medium, provided you give appropriate credit to the original author(s) and the source, provide a link to the Creative Commons license, and indicate if changes were made.

\section{References}

Aavik T, Holderegger R, Bolliger J (2014) The structural and functional connectivity of the grassland plant Lychnis floscuculi. Heredity 112(5):471-478

Alagador D, Cerdeira JO, Araújo MB (2014) Shifting protected areas: scheduling spatial priorities under climate change. J Appl Ecol 51(3):703-713

Ayram CAC, Mendoza ME, Etter A, Salicrup DRP (2016) Habitat connectivity in biodiversity conservation: a review of recent studies and applications. Prog Phys Geogr 40(1):7-37

Bauer DM, Wing IS (2016) The macroeconomic cost of catastrophic pollinator declines. Ecol Econ 126:1-13

Bennett EM, Cramer W, Begossi A, Cundill G, Díaz S, Egoh BN, Geijzendorffer IR, Krug CB, Lavorel S, Lazos E, Lebel L (2015) Linking biodiversity, ecosystem services, and human well-being: three challenges for designing research for sustainability. Curr Opin Environ Sustain $14: 76-85$ 
Blaauw BR, Isaacs R (2014) Larger patches of diverse floral resources increase insect pollinator density, diversity, and their pollination of native wildflowers. Basic Appl Ecol 15(8):701-711

Bommarco R, Biesmeijer JC, Meyer B, Potts SG, Pöyry J, Roberts SP, Steffan-Dewenter I, Öckinger E (2010) Dispersal capacity and diet breadth modify the response of wild bees to habitat loss. Proc $\mathrm{R}$ Soc $\mathrm{B}$ 277(1690):2075-2082

Brown LM, Crone EE (2016) Minimum area requirements for an at-risk butterfly based on movement and demography. Conserv Biol 30(1):103-112

Brückmann SV, Krauss J, Steffan-Dewenter I (2010) Butterfly and plant specialists suffer from reduced connectivity in fragmented landscapes. J Appl Ecol 47(4):799-809

Bunce RG, Bogers MM, Evans D, Halada L, Jongman RH, Mucher CA, Bauch B, de Blust G, Parr TW, OlsvigWhittaker L (2013) The significance of habitats as indicators of biodiversity and their links to species. Ecol Indicators 33:19-25

Calabrese JM, Fagan WF (2004) A comparison-shopper's guide to connectivity metrics. Front Ecol Environ 2(10):529-536

Cameron SA, Lozier JD, Strange JP, Koch JB, Cordes N, Solter LF, Griswold TL (2011) Patterns of widespread decline in North American bumble bees. PNAS 108(2):662-667

Carvell C, Osborne JL, Bourke AF, Freeman SN, Pywell RF, Heard MS (2011) Bumble bee species' responses to a targeted conservation measure depend on landscape context and habitat quality. Ecol Appl 21(5):1760-1771

Crooks KR, Sanjayan M (eds) (2006) Connectivity conservation: maintaining connections for nature. Connectivity conservation. Cambridge University Press, Cambridge, pp 1-21

Crouzeilles R, Beyer HL, Mills M, Grelle CE, Possingham HP (2015) Incorporating habitat availability into systematic planning for restoration: a species-specific approach for Atlantic Forest mammals. Divers Distrib 21(9):1027-1037

Decout S, Manel S, Miaud C, Luque S (2010) Connectivity loss in human dominated landscape: operational tools for the identification of suitable habitat patches and corridors on amphibian's population. Landscape International Conference IUFRO, Sep 2010. Braganca, Portugal, pp 661-666

Doerr VA, Barrett T, Doerr ED (2011) Connectivity, dispersal behaviour and conservation under climate change: a response to Hodgson et al. J Appl Ecol 48(1):143-147

Eriksson A, Elias-Wolff F, Mehlig B, Manica A (2014) The emergence of the rescue effect from explicit within- and between-patch dynamics in a metapopulation. Proc R Soc B 281:20133127

Ewers RM, Didham RK (2007) The effect of fragment shape and species' sensitivity to habitat edges on animal population size. Conserv Biol 21(4):926-936

Forup ML, Henson KS, Craze PG, Memmott J (2008) The restoration of ecological interactions: plant-pollinator networks on ancient and restored heathlands. J Appl Ecol 45(3):742-752

Fourie L, Rouget M, Lötter M (2015) Landscape connectivity of the grassland biome in Mpumalanga, South Africa. Austral Ecol 40(1):67-76

Franklin E, Carroll T, Blake D, Rickard K, Diaz A (2018) Bumble bee forager abundance on lowland heaths is predicated by specific floral availability rather than the presence of honey bee foragers: evidence for forage resource partitioning. J Pollinat Ecol 24(19):172-179

Fuentes-Montemayor E, Goulson D, Park KJ (2011) The effectiveness of agri-environment schemes for the conservation of farmland moths: assessing the importance of a landscape-scale management approach. J Appl Ecol 48(3):532-542

Haddad NM, Brudvig LA, Clobert J, Davies KF, Gonzalez A, Holt RD, Lovejoy TE, Sexton JO, Austin MP, Collins CD, Cook WM (2015) Habitat fragmentation and its lasting impact on Earth's ecosystems. Sci Adv 1(2):e1500052

Hanski I, Ovaskainen O (2003) Metapopulation theory for fragmented landscapes. Theor Popul Biol 64(1):119-127

Heard MS, Carvell C, Carreck NL, Rothery P, Osborne JL, Bourke AFG (2007) Landscape context not patch size determines bumble-bee density on flower mixtures sown for agri-environment schemes. Biol Lett 3(6):638-641

Heller NE, Zavaleta ES (2009) Biodiversity management in the face of climate change: a review of 22 years of recommendations. Biol Conserv 142(1):14-32

Hodgson JA, Kunin WE, Thomas CD, Benton TG, Gabriel D (2010) Comparing organic farming and land sparing: optimizing yield and butterfly populations at a landscape scale. Ecol Lett 13(11):1358-1367

Hodgson JA, Moilanen A, Wintle BA, Thomas CD (2011) Habitat area, quality and connectivity: striking the balance for efficient conservation. J Appl Ecol 48(1):148-152

Hodgson JA, Thomas CD, Wintle BA, Moilanen A (2009) Climate change, connectivity and conservation decision making: back to basics. J Appl Ecol 46(5):964-969

Hopfenmüller S, Steffan-Dewenter I, Holzschuh A (2014) Traitspecific responses of wild bee communities to landscape composition, configuration and local factors. PLoS ONE 9(8):e104439

Jauker F, Diekötter T, Schwarzbach F, Wolters V (2009) Pollinator dispersal in an agricultural matrix: opposing responses of wild bees and hoverflies to landscape structure and distance from main habitat. Landscape Ecol 24(4):547-555

JNCC (2010) Handbook for Phase 1habitat survey: a technique for environmental audit. Joint Nature Conservation Committee, Peterborough

Knight ME, Martin AP, Bishop S, Osborne JL, Hale RJ, Sanderson RA, Goulson D (2005) An interspecific comparison of foraging range and nest density of four bumblebee (Bombus) species. Mol Ecol 14(6):1811-1820

Krauss J, Bommarco R, Guardiola M, Heikkinen RK, Helm A, Kuussaari M, Lindborg R, Öckinger E, Pärtel M, Pino J, Pöyry J (2010) Habitat fragmentation causes immediate and time-delayed biodiversity loss at different trophic levels. Ecol Lett 13(5):597-605

Krewenka KM, Holzschuh A, Tscharntke T, Dormann CF (2011) Landscape elements as potential barriers and corridors for bees, wasps and parasitoids. Biol Consrv 144(6):1816-1825

Kupfer JA (2012) Landscape ecology and biogeography: rethinking landscape metrics in a post-FRAGSTATS landscape. Prog Phys Geogr 36(3):400-420

Lander TA, Klein EK, Stoeckel S, Musch B, Oddou-Muratorio S (2013) Interpreting realized pollen flow in terms of 
pollinator travel paths and land-use resistance in heterogeneous landscapes. Landscape Ecol 28:1769-1783

Menz MH, Phillips RD, Winfree R, Kremen C, Aizen MA, Johnson SD, Dixon KW (2011) Reconnecting plants and pollinators: challenges in the restoration of pollination mutualisms. Trends Plant Sci 16(1):4-12

Merckx T, Marini L, Feber RE, Macdonald DW (2012) Hedgerow trees and extended-width field margins enhance macro-moth diversity: implications for management. J Appl Ecol 49(6):1396-1404

Millennium Ecosystem Assessment (2005) Ecosystems and human well-being: biodiversity synthesis. World Resources Institute, Washington, DC

Moseley D, Smith M, Chetcuti J, de Ioanni M (2008) Falkirk Integrated Habitat Networks. Contract report to Falkirk Council, Forestry Commission Scotland, Scottish Natural Heritage, and Central Scotland Forest Trust

NBN Atlas occurrence download at http://nbnatlas.org. Accessed 4 Jun 2019

Nowakowski M, Pywell RF (2016) Habitat creation and management for pollinators. Centre for Ecology and Hydrology, Wallingford

Öckinger E, Smith HG (2007) Semi-natural grasslands as population sources for pollinating insects in agricultural landscapes. J Appl Ecol 44(1):50-59

Pascual-Hortal L, Saura S (2006) Comparison and development of new graph-based landscape connectivity indices: towards the priorization of habitat patches and corridors for conservation. Landscape Ecol 21(7):959-967

Potts SG, Biesmeijer JC, Kremen C, Neumann P, Schweiger O, Kunin WE (2010) Global pollinator declines: trends, impacts and drivers. Trends Ecol Evolut 25(6):345-353

Sardiñas HS, Tom K, Ponisio LC, Rominger A, Kremen C (2016) Sunflower (Helianthus annuus) pollination in California's Central Valley is limited by native bee nest site location. Ecol Appl 26(2):438-447

Saura S, Bodin Ö, Fortin MJ (2014) Stepping stones are crucial for species' long-distance dispersal and range expansion through habitat networks. J Appl Ecol 51(1):171-182

Saura S, Pascual-Hortal L (2007) A new habitat availability index to integrate connectivity in landscape conservation planning: comparison with existing indices and application to a case study. Landsc Urban Plan 83(2):91-103

Selman P (2009) Conservation designations-are they fit for purpose in the 21st century? Land Use Policy 26:142-153

Smith KM, Loh EH, Rostal MK, Zambrana-Torrelio CM, Mendiola L, Daszak P (2013) Pathogens, pests, and economics: drivers of honey bee colony declines and losses. EcoHealth 10(4):434-445

Smith M, Mosely D, Chetcuti J (2008) Glasgow and clyde valley integrated habitat networks. report to glasgow and clyde valley green network partnership. Forestry Commission, Edinburgh

Spash CL, Simpson IA (1992) Protecting sites of special scientific interest: intrinsic and utilitarian values. Department of Economics, University of Stirling, Stirling
Steffan-Dewenter I (2003) Importance of habitat area and landscape context for species richness of bees and wasps in fragmented orchard meadows. Conserv Biol 17(4):1036-1044

Strachan IM (2017) Manual of terrestrial EUNIS habitats in Scotland. Version 2. Scottish Natural Heritage Commissioned Report No. 766

Tewksbury JJ, Levey DJ, Haddad NM, Sargent S, Orrock JL, Weldon A, Danielson BJ, Brinkerhoff J, Damschen EI, Townsend P (2002) Corridors affect plants, animals, and their interactions in fragmented landscapes. Proc Natl Acad Sci USA 99(20):12923-12926

Vialatte A, Tsafack N, Al Hassan D, Duflot R, Plantegenest M, Ouin A, Villenave-Chasset J, Ernoult A (2017) Landscape potential for pollen provisioning for beneficial insects favours biological control in crop fields. Landscape Ecol 32:465-480

Villemey A, Peterman WE, Richard M, Ouin A, van Halder I, Stevens VM, Baguette M, Roche P, Archaux F (2016) Butterfly dispersal in farmland: a replicated landscape genetics study on the meadow brown butterfly (Maniola jurtina). Landscape Ecol 31:1629-1641

Vos CC, Berry P, Opdam P, Baveco H, Nijhof B, O’Hanley J, Bell C, Kuipers H (2008) Adapting landscapes to climate change: examples of climate-proof ecosystem networks and priority adaptation zones. $J$ Appl Ecol 45(6):1722-1731

WallisDeVries MF, Ens SH (2010) Effects of habitat quality and isolation on the colonization of restored heathlands by butterflies. Restor Ecol 18(3):390-398

Warzecha D, Diekötter T, Wolters V, Jauker F (2016) Intraspecific body size increases with habitat fragmentation in wild bee pollinators. Landscape Ecol 31(7):1449-1455

Watts K, Eycott AE, Handley P, Ray D, Humphrey JW, Quine CP (2010) Targeting and evaluating biodiversity conservation action within fragmented landscapes: an approach based on generic focal species and least-cost networks. Landscape Ecol 25(9):1305-1318

Watts K, Humphrey JW, Griffiths M, Quine C, Ray D (2005) Evaluating biodiversity in fragmented landscapes: principles. Information Note (73)

Wratten SD, Gillespie M, Decourtye A, Mader E, Desneux N (2012) Pollinator habitat enhancement: benefits to other ecosystem services. Agric Ecosyst Environ 159:112-122

Wray JC, Elle E (2015) Flowering phenology and nesting resources influence pollinator community composition in a fragmented ecosystem. Landscape Ecol 30:261-272

Publisher's Note Springer Nature remains neutral with regard to jurisdictional claims in published maps and institutional affiliations. 